\title{
Geographical variation in egg size dimorphism in rockhopper penguins
}

\author{
Laurent Demongin $\cdot$ Maud Poisbleau $\cdot$ \\ Andrea Raya Rey • Adrian Schiavini · Petra Quillfeldt • \\ Marcel Eens · Ian J. Strange
}

Received: 18 June 2009 / Revised: 21 August 2009 / Accepted: 2 September 2009 / Published online: 16 September 2009

(C) The Author(s) 2009. This article is published with open access at Springerlink.com

\begin{abstract}
All crested penguins present a unique reversed hatching asynchrony: the larger second-laid egg (B-egg) hatches before the smaller first-laid egg (A-egg). Although both eggs often hatch, the A-chick generally dies of starvation within days after hatching. However, within rockhopper penguins, the population at the Falkland Islands is unique in that some birds manage to raise both chicks. Although it has been suggested that the egg size dimorphism between A- and B-eggs may explain how long both eggs and chicks survive, this hypothesis has never been explicitly tested. We expect that both eggs are retained longer in the less dimorphic clutches than in the more dimorphic ones. In this paper, we have compiled egg measurements for three rockhopper penguin species (Eudyptes chrysocome, E. filholi and E. moseleyi) in order to compare the intra-clutch egg size dimorphism among these species. Furthermore, we have collected new data to compare egg size dimorphism between two populations of E. chrysocome (Falkland Islands versus Staten Island). A-egg
\end{abstract}

L. Demongin · M. Poisbleau · P. Quillfeldt

Max Planck Institute for Ornithology, Vogelwarte Radolfzell,

Schlossallee 2, 78315 Radolfzell, Germany

M. Poisbleau $(\varangle) \cdot$ M. Eens

Department Biology, Ethology, University of Antwerp,

Campus Drie Eiken, Universiteitsplein 1,

2610 Antwerp (Wilrijk), Belgium

e-mail: maud.poisbleau@ua.ac.be

A. R. Rey · A. Schiavini

Centro Austral de Investigaciones Científicas,

Consejo Nacional de Investigaciones Científicas y Técnicas,

Houssay 200, Ushuaia, Tierra del Fuego, Argentina

I. J. Strange

New Island Conservation Trust, New Island,

FIQQ IZZ, Falkland Islands volumes are more variable between species and populations than B-egg volumes. E. chrysocome and especially the population from the Falkland Islands produces the largest A-eggs and the least dimorphic eggs. Nevertheless, as differences in A-egg volumes between species and between the populations of Falkland Islands and Staten Island are stronger and more significant than differences in egg dimorphism, we suggest that A-egg volume, more than egg dimorphism, could be one of the factors influencing the prevalence of twins. A large A-egg and/or reduced egg dimorphism is probably necessary to enable rockhopper penguins to raise two chicks, but other reasons may also be involved which enable them to keep both eggs and chicks.

Keywords Rockhopper penguin - Egg dimorphism · Geographical variation $\cdot$ Chick survival

\section{Introduction}

All crested penguins (genus Eudyptes) exhibit brood reduction: two eggs are laid but only one chick usually fledges (Stonehouse 1975). They also present a unique reversed hatching asynchrony among birds (Warham 1975): the larger second-laid egg (B-egg) hatches before the smaller first-laid egg (A-egg). Although both eggs often hatch, the A-chick generally dies of starvation within days after hatching (Gwyn 1953; Lamey 1990). The eggs of erectcrested E. sclateri, macaroni E. chrysolophus and royal E. schlegeli penguins are highly dimorphic and generally only one egg hatches as the A-egg is usually lost before the B-egg is laid (Warham 1975; Williams 1980a; St Clair et al. 1995). In comparison, Snares E. robustus and Fiordland E. pachyrhynchus penguins have been shown to be able to raise occasionally two chicks because their eggs are the 
least size dimorphic within the genus Eudyptes (Stonehouse 1971). Indeed, McLean (2000) has suggested that Fiordland penguins could raise twins in $12 \%$ of nests during unusually good years, and at least one pair over 114 nests fledged two chicks (S.M. Phillipson in McLean 2000).

Rockhopper penguins have a circumpolar distribution and are the most widespread of the crested penguins (Fig. 1); they breed on many isolated islands of the Southern oceans (Marchant and Higgins 1990). Like all penguins, they have a high site fidelity to their natal colonies (e.g. Williams 1995). Based on genetic evidence (Jouventin et al. 2006), BirdLife International formally separated in 2007 the Northern rockhopper penguin E. moseleyi from the Southern rockhopper penguin E. chrysocome including the sub-species chrysocome and filholi. To go one step further, a separation into three different species based on molecular, geological and palaeoceanographic data has recently been proposed and validated (Banks et al. 2006; de Dinechin et al. 2009). Therefore, the three rockhopper penguin taxa should now be considered and treated as three different species: E. moseleyi, E. chrysocome and E. filholi.

Only two cases of $E$. filholi raising two chicks have been documented at Campbell Island $\left(52^{\circ} 33^{\prime} \mathrm{S}, 169^{\circ} 09^{\prime} \mathrm{E}\right)$ (Marchant and Higgins 1990) and none for E. moseleyi (Williams 1995). However, at the Falkland Islands $\left(52^{\circ} 00^{\prime} \mathrm{S}, 59^{\circ} 30^{\prime} \mathrm{W}\right)$ it is not unusual for $E$. chrysocome to raise two chicks (Strange 1982; Pütz et al. 2001; Clausen and Pütz 2002). In 2006-2007, for example, three of 114 nests $(2.6 \%)$ raised two chicks until fledging (Poisbleau et al. 2008). In the same breeding population, more than $80 \%$ of pairs retained both eggs until at least one hatched successfully (Strange 1982; Lamey 1993). This proportion is higher than for all other rockhopper penguin populations (20-60\%, Williams 1995). According to the suggestion made by Stonehouse (1971), a possible reason why E. chrysocome in the Falkland Islands retains both eggs until hatching is that their eggs are less dimorphic than those of the other rockhopper penguin populations. If this is the case, the size difference between both chicks at hatching should also be reduced, with the chick size at hatching being correlated with egg size (Warham 1975; Reid and Boersma 1990; Alquati et al. 2007). These cumulative conditions may be necessary to enable A-chicks to compete with B-chicks, the latter being generally favoured by the hatching asynchrony (Lamey 1990; St. Clair 1996).

To test this hypothesis, we have compiled egg measurements for the three species of rockhopper penguins from different populations, and we also provide new egg measurements for E. chrysocome. We first compared the extent of intra-clutch egg dimorphism between species testing whether
Fig. 1 Distribution map for E. moseleyi, E. filholi and E. chrysocome. Circle E. moseleyi, Triangle E. filholi, Square E. chrysocome. Each symbol represents one population. Staten Island is one of the South American islands. No data are available for Auckland, Antipodes and Bounty islands (white triangles without name)

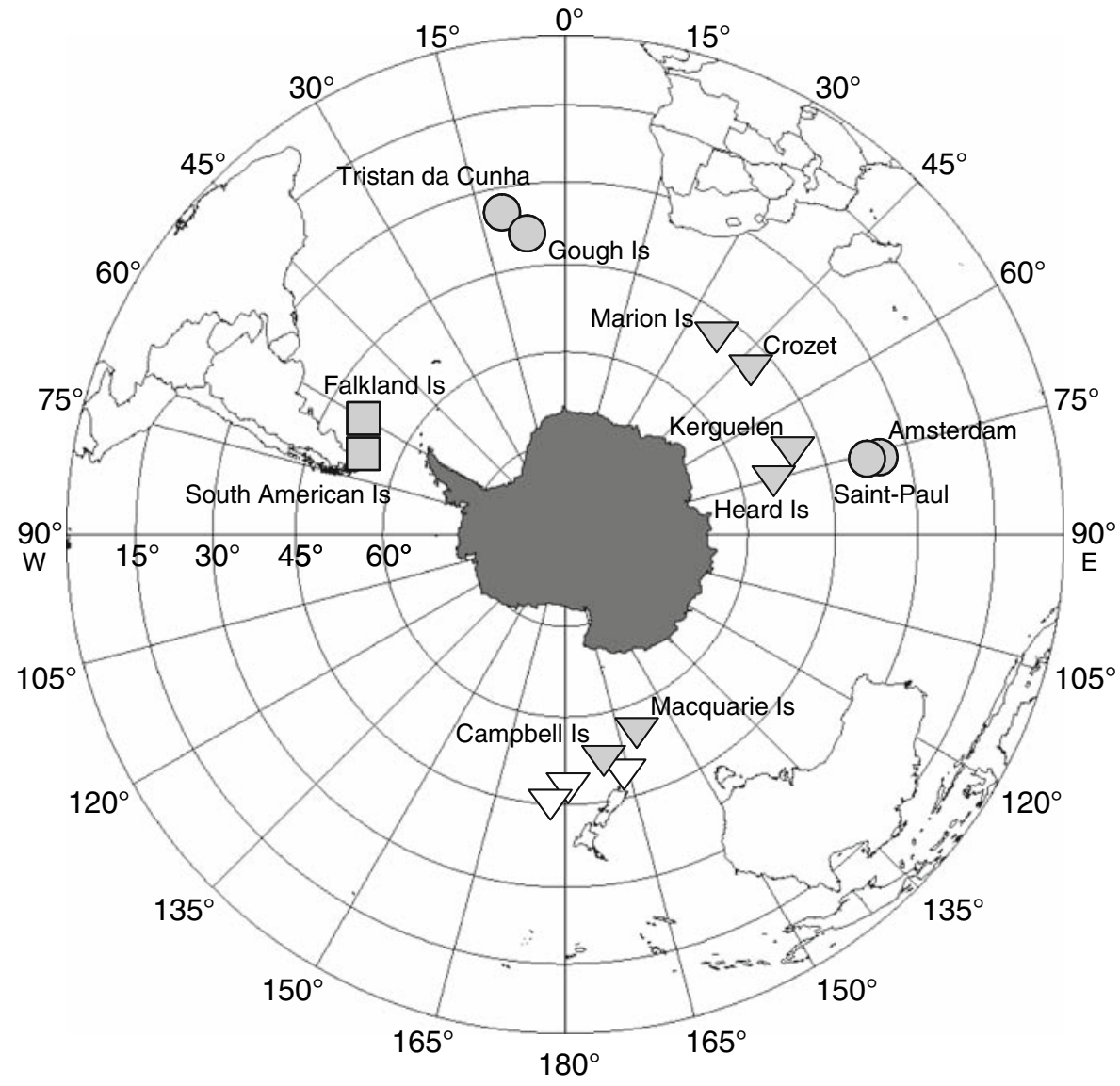


E. chrysocome had lower dimorphic clutches than the two other species. We further examined whether the Falkland Islands population of $E$. chrysocome had lower dimorphic clutches than the Staten Island population of the same species.

\section{Methods}

Egg data were obtained both from field studies and the published literature. As it is extremely rare to obtain individual data from the literature, we, here, dealt with the means supplied by the different studies. In the Falkland Islands, the study was carried out in the "Settlement Colony" on New Island $\left(51^{\circ} 43^{\prime} \mathrm{S}, 61^{\circ} 17^{\prime} \mathrm{W}\right)$ during three consecutive austral summers from October 2006 to November 2008. The colony has approximately 5,000 breeding pairs of $E$. chrysocome. When a new egg was detected, we marked it with a unique code, measured its length and breadth to the nearest $0.1 \mathrm{~mm}$ with vernier callipers and weighed it to the nearest $0.1 \mathrm{~g}$ with a digital balance (for more information see
Poisbleau et al. 2008). In Argentina, the fieldwork was conducted during the austral summer 1998-1999 at Bahía Franklin, Staten Island $\left(54^{\circ} 50^{\prime} \mathrm{S}, 64^{\circ} 40.5^{\prime} \mathrm{W}\right)$, in a subcolony located above the Arroyo Pedro where $>500$ pairs breed (Schiavini 2000).

We calculated egg volume $\left(\mathrm{cm}^{3}\right)$ as length $(\mathrm{cm}) \times$ breadth $^{2}(\mathrm{~cm}) \times 0.512$ (Stonehouse 1966). Although the fresh mass of the egg may be a better indicator of its total size than its volume, the mass data available in the literature are incomplete for a comparison. We, therefore, used egg volumes and the ratio between A-egg volume and B-egg to compare eggs between species and the two E. chrysocome populations.

Two studies present a ratio well outside the range of the other populations (Table 1) and should be considered with caution. For Tristan da Cunha (Williams 1995), the sample size is reduced. Furthermore, contradictory reports on the clutch size of this population have led to the belief that rockhopper penguins lay three eggs, some having unusual size (Williams 1981b); these data come from secondary

Table 1 Egg measurements for E. moseleyis, E. filholi and E. chrysocome (mean)

\begin{tabular}{|c|c|c|c|c|c|c|c|c|c|c|c|c|c|}
\hline \multirow[t]{2}{*}{ Species } & \multirow[t]{2}{*}{ Population } & \multicolumn{2}{|c|}{ Sample size } & \multicolumn{2}{|c|}{ Length (mm) } & \multicolumn{2}{|c|}{ Breadth $(\mathrm{mm})$} & \multicolumn{2}{|c|}{ Mass (g) } & \multicolumn{2}{|c|}{ Volume $\left(\mathrm{cm}^{3}\right)$} & \multirow{2}{*}{$\begin{array}{l}\text { Volume } \\
\text { ratio } \\
\text { A-egg/ } \\
\text { B-egg }\end{array}$} & \\
\hline & & A-egg & B-egg & A-egg & B-egg & A-egg & B-egg & A-egg & B-egg & A-egg & B-egg & & \\
\hline moseleyi & $\begin{array}{c}\text { Tristan da } \\
\text { Cunha }\end{array}$ & 8 & 8 & 63.9 & 71.8 & 46.6 & 56.1 & - & - & 71.0 & 115.7 & 0.61 & Williams (1995)* \\
\hline filholi & Crozet & 23 & 18 & 61.2 & 72.0 & 47.9 & 53.7 & - & - & 71.9 & 106.3 & 0.68 & Despin et al. (1972) \\
\hline filholi & Heard Is & 9 & 9 & 63.6 & 71.7 & 46.2 & 52.9 & 76.1 & 110.8 & 69.5 & 102.7 & 0.68 & Gwynn (1953)** \\
\hline filholi & Heard Is & 13 & 13 & 63.1 & 71.3 & 46.5 & 52.5 & 77.2 & 110.2 & 69.9 & 100.6 & 0.69 & $\begin{array}{l}\text { Woehler and } \\
\text { Gilbert (1990) }\end{array}$ \\
\hline filholi & Marion Is & 122 & 119 & 62.3 & 70.2 & 46.8 & 52.9 & - & - & 69.9 & 100.6 & 0.69 & Williams (1981b) \\
\hline filholi & Marion Is & 9 & 9 & 63.5 & 71.3 & 47.7 & 53.9 & 80.5 & 115.6 & 74.0 & 106.1 & 0.70 & Rand (1954) \\
\hline filholi & Macquarie Is & 7 & 11 & 64.3 & 71.5 & 47.5 & 53.8 & 80.9 & 114.2 & 74.3 & 106.0 & 0.70 & Gwynn (1953) \\
\hline moseleyi & Gough Is & 30 & 30 & 65.2 & 73.0 & 49.2 & 55.2 & - & - & 80.8 & 113.9 & 0.71 & Williams (1980b) \\
\hline filholi & Campbell Is & 41 & 39 & 63.5 & 70.5 & 48.0 & 53.7 & 79.6 & 112.0 & 74.9 & 104.1 & 0.72 & $\begin{array}{l}\text { Marchant and } \\
\text { Higgins (1990) }\end{array}$ \\
\hline filholi & $\begin{array}{l}\text { Crozet and } \\
\text { Kerguelen }\end{array}$ & 31 & 31 & 63.5 & 70.3 & 47.4 & 52.9 & 79.0 & 108.7 & 73.0 & 100.7 & 0.73 & Tollu (1978) \\
\hline filholi & Crozet & 20 & 20 & 63.5 & 70.4 & 47.3 & 52.4 & - & - & 72.7 & 99.0 & 0.73 & Stahl et al. 1985 \\
\hline moseleyi & Amsterdam & 44 & 44 & 63.2 & 70.1 & 49.7 & 54.6 & - & - & 79.9 & 107.0 & 0.75 & $\begin{array}{l}\text { Duroselle and } \\
\text { Tollu (1977) }\end{array}$ \\
\hline moseleyi & $\begin{array}{l}\text { Amsterdam and } \\
\text { Saint-Paul }\end{array}$ & 49 & 49 & 63.4 & 70.4 & 50.0 & 54.6 & 88.4 & 118.4 & 81.2 & 107.5 & 0.76 & Tollu (1978) \\
\hline chrysocome & Staten Is & 14 & 14 & 63.8 & 69.5 & 49.4 & 54.2 & - & - & 80.2 & 104.7 & 0.77 & This study \\
\hline filholi & Macquarie Is & 141 & 130 & 64.0 & 71.0 & 49.0 & 53.0 & 88.2 & 115.2 & 78.7 & 102.1 & 0.77 & Hull et al. (2004) \\
\hline chrysocome & Falkland Is & 545 & 394 & 66.1 & 71.1 & 50.2 & 54.6 & 92.5 & 118.4 & 85.4 & 108.7 & 0.79 & This study \\
\hline chrysocome & Falkland Is & 10 & 10 & 67.2 & 70.7 & 49.4 & 52.5 & - & - & 84.0 & 99.8 & 0.84 & Strange (1982)* \\
\hline
\end{tabular}

Populations are classed according to increasing volume ratio between A-egg volume and B-egg volume. No data are available for Auckland, Antipodes and Bounty islands

* Studies removed from the statistical analysis (see Methods)

** Gwynn (1953) used two types of clutches for weight and measurements: nine clutches were "unselected" and two "additional clutches were selected because of their unusual sizes or shapes". In the present paper, we have kept only the nine "unselected" clutches as the two additional clutches were not appropriate for our aims 
literature without indication of the original source and are not verifiable. In the study of Strange (1982), the eggs were not marked as soon as they were laid; hence it is possible that some eggs have rolled from one nest to another, a frequent case in the New Island colony (pers. obs.), misrepresenting the identity of A- and B-eggs. Moreover, another study with a large sample size in the same colony provided the same egg mass as the present study (A-egg: $91.8 \pm$ $9.36 \mathrm{~g}, n=119$; B-egg: $118.6 \pm 9.27 \mathrm{~g}, n=112$; St. Clair 1996). Therefore, we did not include these two studies in the statistical analysis.

All egg measurements followed a normal distribution (tested with Kolmogorov-Smirnov tests). After examining the correlation of the volumes between A- and B-egg within the three species with a Pearson's correlation, we performed General Linear Models (GLM) based on type III sum of squares with species as fixed factor to test the difference in volumes (A-egg volume, B-egg volume and ratio between both volumes) among the three species. We used post-hoc Tukey HSD tests with species as the grouping variable to highlight the difference between species. Second, we compared egg measurements of the two populations with available individual measurements (i.e. E. chrysocome at Staten and at Falkland Islands) using independentsamples $t$-tests. To obtain comparable sample sizes for the two populations in $t$-tests, we randomly selected $14 \mathrm{~A}$-eggs and $14 \mathrm{~B}$-eggs from the Falkland Islands population.

\section{Results}

Comparison between species

Published data for E. moseleyi, E. filholi and E. chrysocome as well as data from this study are summarised in Table 1

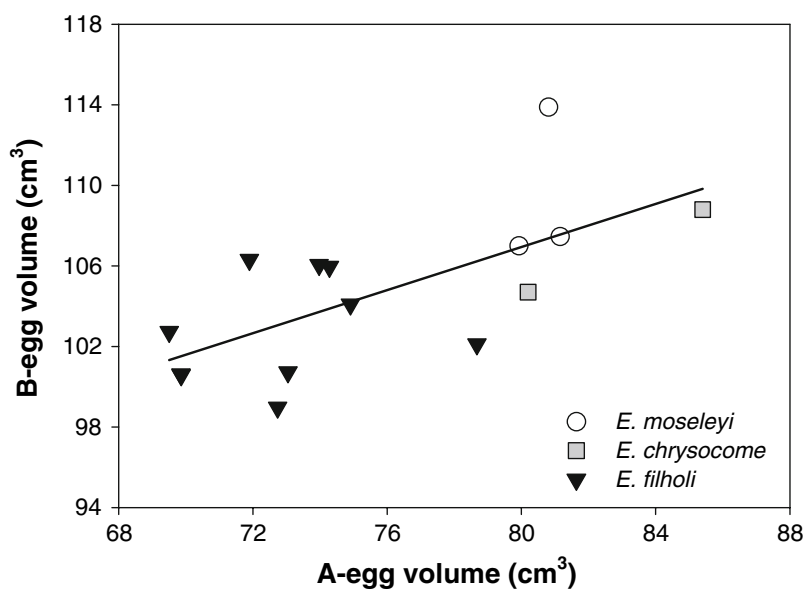

Fig. 2 Relation between the volume of A-eggs and B-eggs for E. moseleyi, E. filholi and E. chrysocome. Each data point represents one population (see Table 1) for each population. Mean volumes of A- and B-eggs are positively correlated within these three species (Pearson Correlation, $r=0.675, P=0.006, N=15$ studies, Fig. 2). The coefficient of variation (CV) between populations is $6.50 \%$ for A-egg volumes and $3.73 \%$ for B-egg volumes. This result shows that A-egg volumes are more variable between different populations for the three species than B-egg volumes (Fig. 2).

We observed a significant difference between species in A-egg volumes, in B-egg volumes and in the ratio between

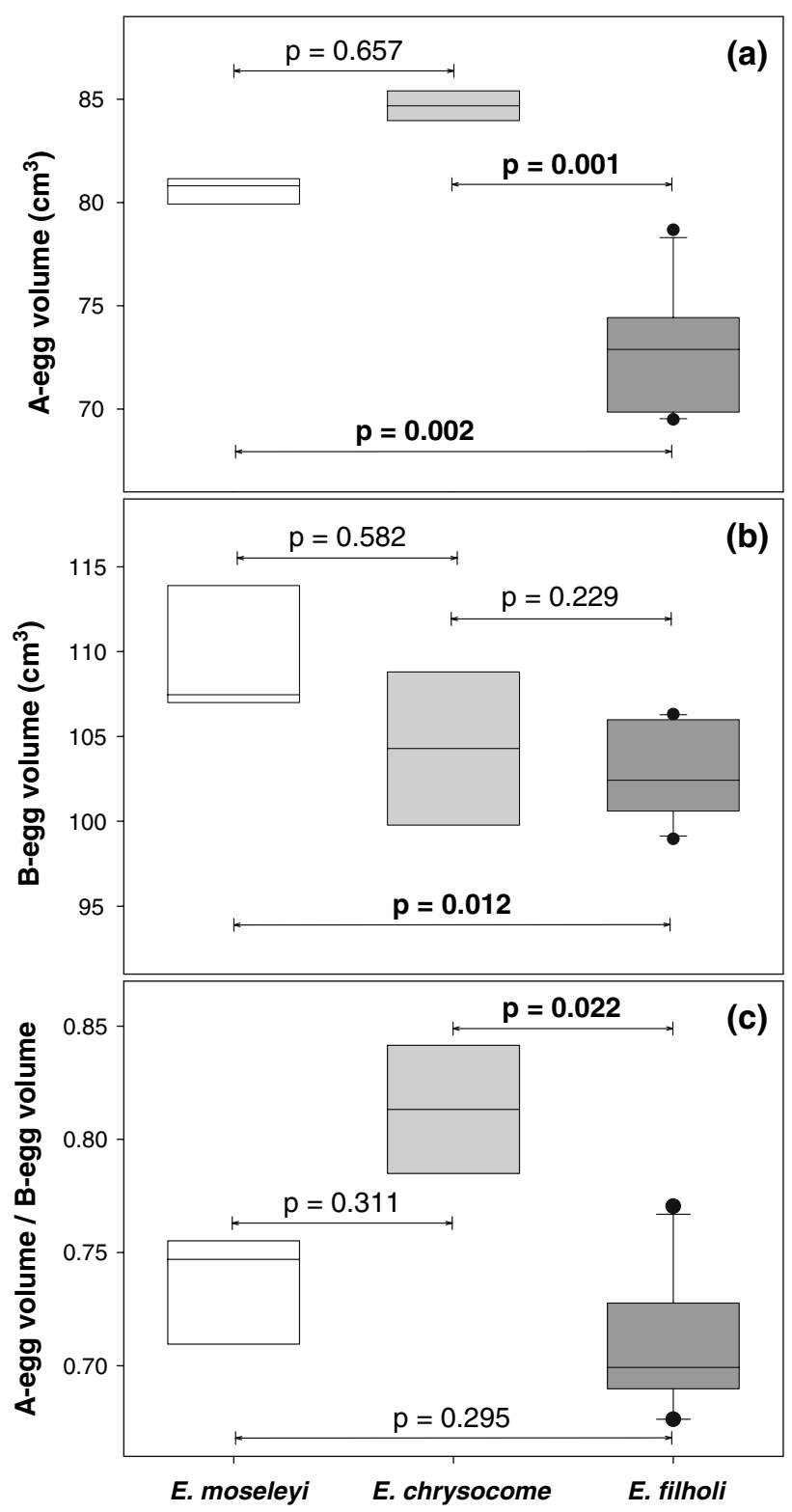

Fig. 3 Differences in a A-egg volumes, $\mathbf{b}$ B-egg volumes and $\mathbf{c}$ ratio between these both volumes according to species. Boxes show medians, 25 and $75 \%$ quartiles; whiskers indicate the range between the 10th and 90th percentiles. Filled circle data outside the 10th and 90th percentiles. Sample sizes are 3, 2 and 10, respectively. Results of post-hoc Tukey HSD tests with species as the grouping variable are presented above or under respective boxes. Significant $P$-values are marked bold 
Table 2 Egg measurements for E. chrysocome (mean $\pm \mathrm{SD}$ )

\begin{tabular}{|c|c|c|c|c|c|c|c|c|c|c|}
\hline \multirow[t]{2}{*}{ Population } & \multicolumn{2}{|c|}{ Sample size } & \multicolumn{2}{|l|}{ Length (mm) } & \multicolumn{2}{|c|}{ Breadth $(\mathrm{mm})$} & \multicolumn{2}{|l|}{ Volume $\left(\mathrm{cm}^{3}\right)$} & \multicolumn{2}{|l|}{ Mass (g) } \\
\hline & A-egg & B-egg & A-egg & B-egg & A-egg & B-egg & A-egg & B-egg & A-egg & B-egg \\
\hline Staten Is & 14 & 14 & $63.8 \pm 3.73$ & $69.5 \pm 2.81$ & $49.4 \pm 2.49$ & $54.2 \pm 1.94$ & $80.2 \pm 12.58$ & $104.7 \pm 10.97$ & - & - \\
\hline Falkland Is & 545 & 394 & $66.1 \pm 2.69$ & $71.1 \pm 2.55$ & $50.2 \pm 1.72$ & $54.6 \pm 1.67$ & $85.4 \pm 8.13$ & $108.7 \pm 9.11$ & $92.5 \pm 8.68$ & $118.4 \pm 9.97$ \\
\hline \multirow[t]{2}{*}{$T$-test } & & & $t_{26}=2.737$ & $t_{26}=1.081$ & $t_{26}=2.287$ & $t_{26}=0.843$ & $t_{26}=2.489$ & $t_{26}=0.987$ & & \\
\hline & & & $P=0.011$ & $P=0.290$ & $P=0.031$ & $P=0.407$ & $P=0.020$ & $P=0.333$ & & \\
\hline
\end{tabular}

We compare egg lengths, breadths and volumes of the two populations of this study using independent-samples $t$-tests. While means and SD are given for the entire dataset, we randomly selected $14 \mathrm{~A}$-eggs and $14 \mathrm{~B}$-eggs from the Falkland Islands population in order to obtain comparable sample sizes for the two populations in $t$-tests

both volumes, the differences in A-egg volumes being more significant than the differences in B-egg volumes and in the ratio $\left(F_{1,12}=17.722 P<0.001, F_{1,12}=6.576, P=0.012\right.$ and $F_{1,12}=5.408, P=0.021$, respectively). E. filholi has the smallest eggs (Fig. 3a and b). E. chrysocome has the largest A-eggs (Fig. 3a), while E. moseleyi has the largest B-eggs (Fig. 3b). As a result, E. chrysocome exhibiting the highest ratio between A-egg volume and B-egg volume has the least dimorphic clutches, while E. filholi exhibiting the lowest ratio has the most dimorphic clutches (Fig. 3c).

Egg characteristics and prevalence of twins in two populations of E. chrysocome

Egg lengths, breadths, volumes and fresh masses of E. chrysocome collected in this study are given in Table 2. A-eggs from the Falkland Islands had significantly greater lengths, breadths and, therefore, also volumes than A-eggs from Staten Island (Table 2, Fig. 4a). However, there was no significant difference between both populations for any of the characteristics of B-eggs (Table 2, Fig. 4b). As a result, even if the ratio between A-egg volume and B-egg volume seems higher for the Falkland Islands than for Staten Island (Fig. 4c), this difference is not significant $\left(t_{26}=1.777, P=0.250\right)$.

For the 2002-2003 and 2003-2004 breeding seasons at Staten Island, the breeding success was, respectively, 31 and 23\% (Raya Rey et al. 2007). These rates were low and no twins were raised. In 2006-2007 in the Falkland Islands, the breeding success was $69 \%$ for 54 nests, and $2.6 \%$ of 114 nests raised two chicks until fledging (Poisbleau et al. 2008).

\section{Discussion}

Variations in volumes

Interestingly, although mean volumes of A- and B-eggs were positively correlated within rockhopper penguins, we observed a higher coefficient of variation in volumes for A-eggs than for B-eggs. We also observed more significant difference between species in A-egg volumes than in B-egg volumes. Similarly, differences between the Falkland Islands and the Staten Island populations were significant for A-eggs, while they were not for B-eggs. All these observations indicate that B-egg volumes are more consistent between species and populations than A-egg volumes are, the latter being twice more variable than B-eggs. This also means that differences in volume dimorphism between A- and B-eggs are mainly driven by variation in A-egg volumes.

Intra-clutch egg dimorphism between species

As a result of differences in egg volumes, we observed that E. filholi had the most dimorphic eggs while E. chrysocome has the least dimorphic ones. Among all populations of rockhopper penguins (Table 1), we similarly noted that the least dimorphic eggs were those from the Falkland Island population. In this study, the A-egg averaged 0.79 of the B-egg volume, a value between the Snares penguin and the Fiordland penguin species $(0.77$ and 0.85, respectively, Warham 1974a, b; Massaro and Davis 2005). This population has, therefore, the second least dimorphic eggs of all crested penguins after the Fiordland penguin. The trend for E. chrysocome to have less dimorphic eggs than others was also confirmed by the data from Staten Island that were equalled only by those of one study from Macquarie Island (Hull et al. 2004), although another study from this population found a much higher egg dimorphism (Gwynn 1953).

The species with highly dimorphic eggs (erectcrested, macaroni and royal penguins; A-egg/B-egg volume: 0.55-0.64; Gwynn 1953; Williams 1995) almost never keep both eggs until hatching, while the species with more equal eggs (Snares and Fiordland penguins; 0.77-0.85, Warham 1974a, b) often hatch two chicks (Warham 1975; St. Clair et al. 1995). Rockhopper penguins present an intriguing intermediate pattern with significant differences between species and populations. 

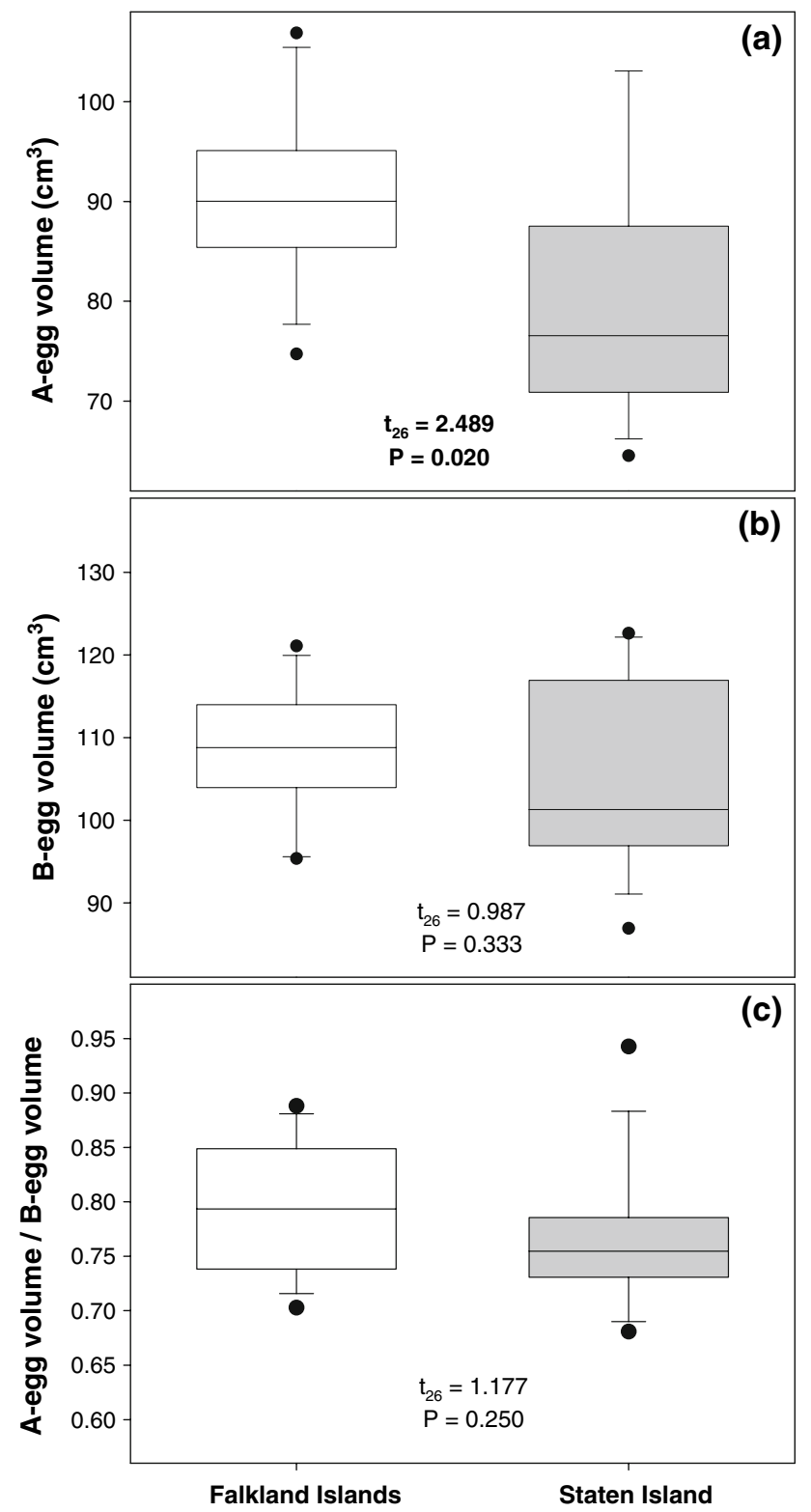

Fig. 4 Differences in a A-egg volumes, b B-egg volumes and $\mathbf{c}$ ratio between both of these volumes between Falkland Islands and Staten Island. Boxes show medians, 25 and $75 \%$ quartiles; whiskers indicate the range between the 10th and 90th percentiles. Filled circle data outside the 10th and 90th percentiles. Sample sizes are 14 for both populations. Results of $t$-tests with population as the grouping variable are presented under respective boxes. Significant $P$-values are marked bold

Interestingly, E. chrysocome from the Falkland Islands presents the higher hatching rate of both eggs and is the only rockhopper population likely to rear two chicks (Lamey 1993; Williams 1995; Poisbleau et al. 2008). Our results fit well the Stonehouse's hypothesis that intra-clutch egg dimorphism could influence the prevalence of twins in a population (Stonehouse 1971).

The fact that the difference in egg dimorphism between the E. chrysocome populations from Falkland Islands and Staten Island was not significant does not corroborate this hypothesis. However, A-eggs from the Falkland Islands population are significantly larger than A-eggs from Staten Island, while no significant difference was detected for B-eggs. Moreover, the A-eggs from the Falkland Islands were the largest of all the populations. This result could explain the higher hatching rate for A-eggs and the higher survival rate for A-chicks in this population. Thus, we can suppose that the A-egg volume, whether in combination with the B-egg volume through the egg dimorphism or not, could be a factor influencing the prevalence of twins in a population.

In most avian species, egg size appears to be an individual characteristic, with the effects of age, female body condition or food availability having only a small effect on this trait (Christians 2002). Although we cannot exclude that the accumulation of these effects could bias egg size, especially when sample size is small, the potential impact is probably slight and not measurable, and therefore does not affect the overall patterns described here. Many hypotheses have been proposed to explain why the first-laid egg is smaller than the second (see for example Williams 1980a; Johnson et al. 1987; Williams 1989; Johnson and Bednarz 1989; Williams 1990; Lamey 1993; St. Clair 1998 and see Williams 1995 for a review), but no consensus was reached yet. Williams (1990) suggested that egg-size dimorphism in the genus Eudyptes tends to be greater at higher latitudes. If this hypothesis is valid for rockhopper penguins, E. moseleyi should have the least dimorphic eggs and $E$. chrysocome the most dimorphic, which is clearly not supported by our results.

Prevalence of twins

Factors explaining the amount of time two chicks may coexist are numerous. The most important one is probably the degree of hatching asynchrony (Williams 1980a; Williams 1981a; Lamey 1990): the larger the size difference between both chicks, the less the smallest chick may survive. This difference may be reduced if the egg dimorphism is low and/or if the time elapsed between both hatchings is short (Seddon and van Heezik 1991a, b; Williams and Croxall 1991; Moreno et al. 1994). When twins are present in the nest, an important factor in their survival may be the ability of the parents to provide a substantially greater amount of food than if they were rearing only one chick (Warham 1974b). In this context, the distance to foraging grounds and the food availability are probably important determinants for the reproductive performance and these may vary annually (Raya Rey et al. 2007). Differences in the degree of predation, often by skuas, are also responsible for egg and chick loss and may vary strongly between colonies (Williams 1980b; St. Clair and St. Clair 1996). 
Given all of these factors, even if both eggs are able to hatch in many populations of rockhopper penguins, the probability that twins reach the fledging age remains low. It is possible that the overall situation would be more favourable in the Falkland Islands than in other populations. Thus, the breeding success for E. moseleyi and E. filholi is usually less than 0.61 chicks per breeding pair (Williams 1980b; Williams 1995), while the average per year can be as high as 0.95 chick per breeding pair in the Falkland Islands (Huin 2005). Although rearing twins to fledging is undoubtedly a rare event in rockhopper penguins, this phenomenon should receive more attention and it can no longer be stated that it never occurs. Clearly, the study of the prevalence of twins in other populations could help to clarify our understanding of the reversed hatching asynchrony in the crested penguins.

Acknowledgments We are grateful to the New Island Conservation Trust for permission to work on the island. We wish to thank Maria and Georgina Strange and Dan Birch for their support during the field season. Thanks also to Helen Otley, Falkland Islands Government and British Antarctic Survey for their logistic help. The Falkland Islands study was funded by grants provided by the Deutsche Forschungsgemeinschaft DFG (Qu 148/1-ff) and by the FWO Flanders, Belgium and was approved by the Falkland Islands Government (Environmental Planning Office). The Staten Island project was possible with the support of the Consejo Nacional de Investigaciones Científicas y Técnicas and René Portal (Total Austral). The manuscript benefited greatly from critical comments by Dieter Piepenburg, Barbara Wienecke, Colleen C. St. Clair, Josie Meaney and two anonymous reviewers.

Open Access This article is distributed under the terms of the Creative Commons Attribution Noncommercial License which permits any noncommercial use, distribution, and reproduction in any medium, provided the original author(s) and source are credited.

\section{References}

Alquati AB, Rubolini D, Romano M, Boncoraglio G, Fasola M, Saino $\mathrm{N}$ (2007) Effects of egg albumen removal on yellow-legged gull chicks phenotype. Funct Ecol 21:310-316

Banks J, Van Buren A, Cherel Y, Whitfield JB (2006) Genetic evidence for three species of rockhopper penguins, Eudyptes chrysocome. Polar Biol 30:61-67

Christians JK (2002) Avian egg size: variation within species and inflexibility within individuals. Biol Rev 77:1-26

Clausen AP, Pütz K (2002) Recent trends in diet composition and productivity of gentoo, magellanic and rockhopper penguins in the Falkland Islands. Aquat Conserv Mar Freshw Ecosyst 12:51-61

de Dinechin M, Ottvall R, Quillfeldt P, Jouventin P (2009) Speciation chronology of rockhopper penguins inferred from molecular, geological and palaeoceanographic data. J Biogeogr 36:693-702

Despin B, Mougin JL, Segonzac M (1972) Oiseaux et mammifères de l'Ile de 1'Est. Archipel Crozet $\left(46^{\circ} 25^{\prime} \mathrm{S}, 52^{\circ} 12^{\prime} \mathrm{E}\right)$. Comité National Français des Recherches Antarctiques 31:1-106

Duroselle T, Tollu B (1977) The rockhopper penguin Eudyptes chrysocome moseleyi of Saint Paul and Amsterdam Islands. In: Llano G (ed) Adaptation within Antarctic ecosystem. Smithsonian Institution, Washington DC, pp 579-604
Gwynn AM (1953) The egg-laying and incubation periods of rockhopper, macaroni and gentoo penguins. ANARE Rep Ser B 1:1-29

Huin N (2005) Falkland Island seabird monitoring programmeAnnual report 2003-2004 \& 2004-2005. Falklands Conservation

Hull CL, Hindell M, le Mar K, Scofield P, Wilson J, Lea M-A (2004) The breeding biology and factors affecting reproductive success in rockhopper penguins Eudyptes chrysocome at Macquarie Island. Polar Biol 27:711-720

Johnson K, Bednarz JC (1989) Crested penguin egg dimorphism: reply to Williams. Oikos 55:141-142

Johnson K, Bednarz JC, Zack S (1987) Crested penguins: why are first eggs smaller? Oikos 49:347-349

Jouventin P, Cuthbert RJ, Ottvall R (2006) Genetic isolation and divergence in sexual traits: evidence for the northern rockhopper penguin Eudyptes moseleyi being a sibling species. Mol Ecol 15:3413-3423

Lamey TC (1990) Hatch asynchrony and brood reduction in penguins. In: Davis LS, Darby JT (eds) Penguin biology. Academic Press, San Diego, pp 399-416

Lamey TC (1993) Territorial aggression, timing of egg loss, and eggsize differences in rockhopper penguins, Eudyptes c. chrysocome, on New Island, Falkland Islands. Oikos 66:293-297

Marchant S, Higgins PJ (1990) Handbook of Australian, New Zealand and Antarctic birds, Volume 1 Ratites to ducks. Part A Ratites to petrels. Oxford University Press, Melbourne

Massaro M, Davis LS (2005) Differences in egg size, shell thickness, pore density, pore diameter and water vapour conductance between first and second eggs of Snares penguins Eudyptes robustus and their influence on hatching asynchrony. Ibis 147:251-258

McLean IG (2000) Breeding success, brood reduction and the timing of breeding in the Fiordland crested penguin (Eudyptes pachyrhynchus). Notornis 47:55-58

Moreno J, Carrascal LM, Sanz JJ, Amat JA, Cuervo JJ (1994) Hatching asynchrony, sibling hierarchies and brood reduction in the chinstrap penguin Pygoscelis antarctica. Polar Biol 14:21-30

Poisbleau M, Demongin L, Strange IJ, Otley H, Quillfeldt P (2008) Aspects of the breeding biology of the southern rockhopper penguin Eudyptes c. chrysocome and new consideration on the intrinsic capacity of the A-egg. Polar Biol 31:925-932

Pütz K, Ingham RJ, Smith JG, Croxall JP (2001) Population trends, breeding success and diet composition of gentoo Pygoscelis papua, magellanic Spheniscus magellanicus and rockhopper Eudyptes chrysocome penguins in the Falkland Islands. Polar Biol 24:793-807

Rand RW (1954) Notes on the birds of Marion Island. Ibis 96:173-206

Raya Rey A, Trathan P, Schiavini A (2007) Inter-annual variation in provisioning behaviour of southern rockhopper penguins Eudyptes chrysocome chrysocome at Staten Island, Argentina. Ibis 149:826-835

Reid WV, Boersma PD (1990) Parental quality and selection on egg size in the magellanic penguin. Evolution 44:1780-1786

Schiavini A (2000) Staten Island, Tierra del Fuego: the largest breeding ground for Southern rockhopper penguins? Waterbirds 23:286-291

Seddon PJ, van Heezik Y (1991a) Effects of hatching order, sibling asymmetries and nest site on survival analysis of jackass penguin chicks. Auk 108:548-555

Seddon PJ, van Heezik Y (1991b) Hatching asynchrony and brood reduction in the jackass penguin: an experimental study. Anim Behav 42:347-356

St. Clair CC (1996) Multiple mechanisms of reversed hatching asynchrony in rockhopper penguins. J Anim Ecol 65:485-494

St. Clair CC (1998) What is the function of first eggs in crested penguins? Auk 115:478-482

St. Clair CC, St. Clair RC (1996) Causes and consequences of egg loss in rockhopper penguins, Eudyptes chrysocome. Oikos 77:459-466 
St. Clair CC, Waas JR, St. Clair RC, Boag PT (1995) Unfit mothers? Maternal infanticide in royal penguins. Anim Behav 50:11771185

Stahl J-C, Derenne P, Jouventin P, Mougin JL, Teulières L, Weimerskirch H (1985) Le cycle reproducteur des gorfous de l'Archipel Crozet : Eudyptes chrysolophus, le gorfou macaroni et Eudyptes chrysocome, le gorfou sauteur. L'Oiseau et RFO 55:2743

Stonehouse B (1966) Egg volumes from linear dimensions. Emu 65:227-228

Stonehouse B (1971) The Snares Islands penguin Eudyptes robustus. Ibis 113:1-7

Stonehouse B (1975) Introduction: the Spheniscidae. In: Stonehouse B (ed) The biology of penguins. The Macmillan Press, London, pp $1-15$

Strange IJ (1982) Breeding ecology of the rockhopper penguin (Eudyptes crestatus) in the Falkland Islands. Gerfaut 72:137-188

Tollu B (1978) Contribution à l'étude des Sphénicidés du genre Eudyptes dans les îles australes françaises (Amsterdam, SaintPaul, Crozet, Kerguelen). Dissertation, Université Paris VII

Warham J (1974a) The breeding biology and behaviour of the Snares crested penguin. J R Soc NZ 4:63-108

Warham J (1974b) The Fiordland crested penguin Eudyptes pachyrhynchus. Ibis 116:1-27
Warham J (1975) The crested penguins. In: Stonehouse B (ed) The biology of penguins. The Macmillan Press, London, pp 189-269

Williams AJ (1980a) Offspring reduction in macaroni and rockhopper penguins. Auk 97:754-759

Williams AJ (1980b) Rockhopper penguins Eudyptes chrysocome at Gough Island. Bull BOC 100:208-212

Williams AJ (1981a) Growth and survival of artificially twinned rockhopper penguin chicks. Cormorant 9:8-12

Williams AJ (1981b) The clutch size of macaroni and rockhopper penguins. Emu 81:87-90

Williams TD (1989) Aggression, incubation behaviour and egg-loss in macaroni penguins, Eudyptes chrysolophus, at South Georgia. Oikos 55:19-22

Williams TD (1990) Growth and survival in macaroni penguin, Eudyptes chrysolophus, A- and B-chicks: do females maximise investment in the large B-egg? Oikos 59:349-354

Williams TD (1995) The penguins. Oxford University Press, Oxford

Williams TD, Croxall JP (1991) Chick growth and survival in gentoo penguins (Pygoscelis papua): effect of hatching asynchrony and variation in food supply. Polar Biol 11:197-202

Woehler EJ, Gilbert CA (1990) Hybrid rockhopper-macaroni penguins, interbreeding and mixed species pairs at Heard and Marion Islands. Emu 90:198-201 